\title{
Efeitos do exercício sobre a regeneração do nervo isquiático de ratos Wistar após axonotmese
}

\author{
Effects of physical exercise on sciatic nerve regeneration in \\ Wistar rats after axonotmesis
}
Efectos del ejercicio físico sobre la regeneración nerviosa en ratas Wistar sometidas a axonotmesis del nervio ciático

\author{
Denis Guilherme Guedert ${ }^{1}$, Edison Sanfelice André2
}

1.Fisioterapeuta, Mestre em Fisiologia, Laboratório de Fisioterapia Neurológica Experimental (LFNE). Departamento de Fisioterapia, Universidade Regional de Blumenau (FURB). BlumenauSC, Brasil.

2.Fisioterapeuta, Doutor em Neurociências, Laboratório de Fisioterapia Neurológica Experimental (LFNE). Departamento de Fisioterapia, Universidade Regional de Blumenau (FURB). Blumenau-SC, Brasil.

\begin{abstract}
Resumo
Introdução. Lesões do sistema nervoso periférico são comuns e acarretam perdas tanto sensitivas quanto motoras. Tais lesões interferem na vida do indivíduo devido à diminuição do rendimento profissional. O exercício físico é um dos meios empregados no tratamento das lesões nervosas periféricas. Objetivos. Objetivamos estudar os efeitos do exercício físico (nado forçado) em ratos submetidos a axonotmese. Método. Neste estudo utilizamos quatro grupos: G1 - grupo controle sedentário, G2 - Grupo submetido ao exercício diariamente durante 21 dias iniciando 24 horas após a lesão nervosa, G3 - grupo submetido ao exercício 7 dias após a lesão durante 14 dias consecutivos, G4 - grupo submetido ao exercício 24 horas após a lesão, durante 21 dias, porém em dias alternados. Resultados. Nossos dados apontam para uma melhora funcional observada através do índice funcional do isquiático, incremento na produção de fatores neurotróficos (BDNF e NGF) e diminuição da expressão da enzima iNOS e da citocina TNF-a nos grupos exercitados. Conclusão. O exercício físico na forma em que foi empregado melhorou a função motora e acelerou e a regeneração nervosa periférica.

Unitermos. Lesão nervosa periférica; axonotmese; exercício físico; nervo isquiático; regeneração nervosa
\end{abstract}

\footnotetext{
Abstract

Introduction. Peripheral nerve injuries are common and cause both sensory and motor losses. Such injuries interfere in the individual's quality of life due to the decrease in personal and professional performance. Physical exercise is a common strategy to treat peripheral nerve injuries. Objective. We aimed to study the effects of physical exercise (forced swimming) in Wistar rats submitted to axonotmesis. Method. In this study we used four groups: G1 sedentary control group, G2 - Group submitted to exercise in daily basis for 21 days starting 24 hours after the axonotmesis, G3 - group submitted to exercise 7 days after the axonotmesis for 14 consecutive days, G4 - group submitted to exercise 24 hours after the axonotmesis, for 21 days, but on alternate days. Results. Our data shows a functional improvement observed through the sciatic function index, an increase in the neurotrophic factors (BDNF and NGF) production and a decrease in the expression of the iNOS enzyme and the TNF-a cytokine in the exercised groups. Conclusion. Physical exercise as it was employed improved motor function recovery and accelerated peripheral nerve regeneration.

Keywords. Peripheral nerve injury; axonotmesis; physical exercise; sciatic nerve; nerve regeneration
} 


\section{Resumen}

Introducción. Las lesiones del sistema nervioso periférico son comunes y causan pérdidas tanto sensoriales como motoras. Estas lesiones interfieren en la vida del individuo debido a la disminución del desempeño profesional. El ejercicio físico es uno de los medios utilizados para tratar las lesiones de los nervios periféricos. Objetivo. Estudiar los efectos del ejercicio físico (natación forzada) en ratas sometidas a lesión nerviosa por compresión (axonotmesis). Método. En este estudio utilizamos cuatro grupos: G1 - grupo de control sedentario, G2 grupo sometido a ejercicio diario durante 21 días a partir de las 24 horas posteriores a la lesión nerviosa, G3 - grupo sometido a ejercicio 7 días después de la lesión durante 14 días consecutivos, G4 - grupo sometido a hacer ejercicio 24 horas después de la lesión, durante 21 días, pero en días alternos. Resultados. Nuestros datos apuntan a una mejora funcional observada a través del índice funcional del ciático, un aumento en la producción de factores neurotróficos (BDNF y NGF) y disminución en la expresión de la enzima iNOS y de la citocina TNF-a en los grupos ejercitados. Conclusión. El ejercicio físico en la forma en que se empleó mejoró la función motora y aceleró la regeneración de los nervios periféricos.

Palabras clave. Lesión del nervio periférico; axonotmesis; ejercicio físico; nervio ciático; regeneración nerviosa

Trabalho realizado na Universidade Regional de Blumenau (FURB). Blumenau-SC. Brasil.

\section{INTRODUÇÃO}

Lesões nervosas periféricas são comuns na sociedade industrializada e por vezes incapacitantes ${ }^{1,2}$. Tais lesões classificam-se em neuropraxia, axonotmese e neurotmese, conforme o grau de ruptura sofrido pela fibra nervosa ${ }^{3}$.

Quando o axônio perde a continuidade com o corpo celular, tal qual ocorre na axonotmese, ele passa pelo processo conhecido como degeneração Walleriana ${ }^{4-6}$. A degeneração Walleriana desencadeia uma forte resposta inflamatória, onde as células de Schwann tem papel importante ${ }^{7}$. Estas células induzem a produção de citocinas pró-inflamatórias tais como fator de necrose tumoral (TNFa) ${ }^{8}$.

É importante destacar, também, o papel da enzima óxido nítrico sintase (NOS), responsável pela produção de 
óxido nítrico (NO). Esta molécula pode apresentar efeitos protetores no sistema nervoso, no entanto, há evidências de que níveis aumentados resultem em citotoxicidade ${ }^{9,10}$.

Após lesão, a expressão de NOS aumenta drasticamente ${ }^{11}$, retardando 0 processo regenerativo $e$ potencializando o processo inflamatório e a dor neuropática ${ }^{12}$.

Outra resposta fisiológica encontrada após a axonotmese é a produção dos fatores neurotróficos Brain Derived Neurotrophic Factor (BDNF) e Nerve Grouth Factor $(\mathrm{NFG})^{13,14}$ importantes no desenvolvimento, manutenção e plasticidade do sistema nervoso ${ }^{15}$. Imediatamente após a lesão nervosa, a expressão destes fatores encontra-se aumentada ${ }^{16 .}$

Há inúmeras evidências de que o exercício possa acelerar o processo regenerativo, não produzir nenhum efeito, e até mesmo atrasá-lo, e esses resultados parecem ser dependentes do momento em que se iniciam os exercícios ${ }^{4,5,17-21}$. O número de evidências que apontam para respostas favoráveis à regeneração do tecido nervoso periférico após exercícios físicos está relacionado à expressão potencializada de BDNF e $\mathrm{NGF}^{22}$, além da inibição da expressão de TNF-a e iNOS.

Diante disso, objetivou-se estudar os possíveis efeitos do nado forçado sobre o processo de regeneração nervosa periférica em ratos Wistar submetidos à axonotmese do nervo isquiático. 


\section{MÉTODO}

\section{Amostra}

A amostra foi constituída por 36 ratos Wistar machos adultos, com peso entre 250 e $350 \mathrm{~g}$, provenientes do biotério central da Universidade Regional de Blumenau.

Durante o processo de experimentação, os animais permaneceram no biotério setorial do laboratório (ciclo claroescuro de 12 horas - 7:00h às 19:00h claro sob luz artificial e temperatura controlada $\left(24^{\circ} \mathrm{C} \pm 2\right)$, alojados em gaiolas individuais dentro de uma estante ventilada, e receberam livremente água filtrada e ração sólida da marca Nuvilab ${ }^{\circledR}$. Os experimentos foram precedidos por 10 dias de ambientação ao laboratório durante o qual os animais foram submetidos às condições de coleta do Índice Funcional do Ciático e do nado forçado (durante 10min cada atividade).

Os animais foram submetidos a axonotmese e divididos aleatoriamente em 4 grupos como segue: O grupo 1 (G1, $\mathrm{n}=9$ ) foi constituído por animais sedentários que permaneceram 21 dias sem nado forçado; 0 grupo 2 (G2, $\mathrm{n}=9$ ) realizou nado forçado iniciando 24 horas após a lesão durante 21 dias consecutivos, $45 \mathrm{~min} /$ dia; O grupo 3 (G3, $\mathrm{n}=9$ ) iniciou nado forçado sete dias após a lesão durante 14 dias consecutivos, por $45 \mathrm{~min} / \mathrm{dia}^{23}$; O grupo $4(\mathrm{G} 4, \mathrm{n}=9)$ iniciou nado forçado 24 horas após a lesão e alternadamente dentro de um período de 21 dias por $45 \mathrm{~min} /$ dia. O nado foi realizado em um recipiente de plástico com dimensões de $33 \mathrm{~cm} \times 54 \mathrm{~cm} \times$ e $35 \mathrm{~cm}(\mathrm{~L} / \mathrm{C} / \mathrm{A})$, dividido ao meio com uma placa de alumínio de maneira que dois animais pudessem 
nadar simultaneamente e de forma individualizada. A água era mantida a uma temperatura constante de $34^{\circ} \mathrm{C}$.

Todos os procedimentos aqui descritos foram previamente aprovados pela Comissão de Ética em Utilização de Animais da Universidade Regional de Blumenau (CEUAFURB - protocolo 017/2018).

\section{Procedimento}

Procedimento cirúrgico

Os animais foram anestesiados com uma dose fixa de $0,1 \mathrm{ml}$ de cloridrato de xilazina (Rompun, Bayer ${ }^{\circledR}$ ) e uma dose de cloridrato de cetamina (Ketamin, Cristália ${ }^{\circledR}$ ), 0,3 $\mathrm{ml} / 100 \mathrm{~g}$ (75mg/Kg) via intraperitoneal (i.p.). Após averiguação da profundidade da sedação através do pinçamento das pregas interdigitais, realizou-se tricotomia da região dorsolateral da coxa direita, divulsão da musculatura lateral da coxa e pinçamento do nervo isquiático em seu ponto médio antes da bifurcação em nervo tibial e fibular comum com o auxílio de uma pinça hemostática durante 30 segundos. Neste período, a cremalheira da pinça permaneceu travada no terceiro nível.

\section{Análise funcional}

Para a análise funcional utilizamos a fórmula do índice funcional do ciático (IFC), modificada ${ }^{24}$. Este índice reflete 0 grau de funcionalidade motora através da análise matemática comparativa entre a pata normal e a pata lesionada ${ }^{24}$. A obtenção dos valores referentes ao IFC 
ocorreu através da captura em vídeo (formato 16:9, resolução de 490.000 pixels - Sony ${ }^{\circledR}$ Handycam DCR-SR45), a $60 \mathrm{~cm}$ de distância da passarela $(45 \times 9 \times 30 \mathrm{~cm})$ onde os ratos realizavam a marcha. Esta possuía um fundo cego escuro em uma das extremidades para onde o animal é atraído. O piso de acrílico transparente quadriculado com intervalos de $1 \times 1 \mathrm{~cm}$, serviu de referência para as medições. Abaixo deste piso havia um espelho posicionado em $45^{\circ}$ que permitia a vista ventral do animal enquanto deambulava.

As aquisições dos vídeos foram realizadas nos períodos de 24 horas, $7^{\circ}$ dia, $14^{\circ}$ dia e $21^{\circ}$ dia pós-lesão. Foram extraídas imagens estáticas das patas posteriores durante a fase de apoio das quais foram coletadas as medidas necessárias para o cálculo do IFC $^{23}$ através do software Image ${ }^{\circledR}$. As medidas foram inseridas em uma planilha do software Statistica ${ }^{\circledR}$ (ver. 8.0, Statsoft, Inc.) para a obtenção dos valores de IFC e posteriormente submetidas à ANOVA de uma via, teste de Levene para homogeneidade de variâncias e o teste de Tukey caso houvesse significância $(p \leq 0,05)$.

\section{Análise biomolecular}

Para a coleta do material, os animais foram eutanasiados com sobredosagem anestésica com cloridrato de cetamina (Ketamin, Cristália ${ }^{\circledR}$ ). O Epicentro da lesão nervosa foi removido e processado para análise da expressão gênica (rt-PCR) dos fatores neurotróficos BDNF, NGF, da enzima iNOS e da citocina TNF-a. Foi separado das demais partes do nervo e macerado com bisturi estéril, colocado em 
um microtubo tipo Eppendorf de 1,5ml onde foi adicionado 0,5ml de brazol (Brazol ${ }^{\circledR}$, LGC Biotecnologia). Em seguida, o tubo foi agitado por aproximadamente 2 min e foi feita adição de $0,125 \mathrm{ml}$ de clorofórmio gelado com o intuito de separar a porção orgânica da aquosa. O material foi então misturado por mais dois minutos, onde então seguiu para a centrifugação por 20min na velocidade de $12.000 \mathrm{rpm}$ e temperatura de $4^{\circ} \mathrm{C}$.

Terminada a primeira centrifugação, a camada superior aquosa contendo o RNAm foi retirada e transferida para um tubo estéril e recebeu a adição de $0,250 \mathrm{ml}$ de isopropanol (Isopropanol, Quimidrol). O material permaneceu incubado por 10 minutos até a segunda centrifugação em velocidade de $12.000 \mathrm{rpm}, 4^{\circ} \mathrm{C}$, durante $10 \mathrm{~min}$.

Após, o isopropanol foi desprezado, realizou-se a adição de $0,500 \mathrm{ml}$ de etanol a $70 \%$, seguida de nova centrifugação em velocidade de 7.500rpm durante $5 \mathrm{~min}$ com temperatura de $4^{\circ} \mathrm{C}$. Ao final da terceira centrifugação, o etanol foi descartado e os tubos em estufa para secagem (10min, $40^{\circ} \mathrm{C}$ ) e foram adicionados $100 \mu \mathrm{l}$ de água livre de RNAses (Ultra-Pure Water, Gibco ${ }^{\circledR}$ ) e os tubos foram armazenados em temperatura de $-80^{\circ} \mathrm{C}$.

O sistema de detecção (StepOne $®$, Applied Biosystems, USA) utilizado para quantificação da expressão de RNAm foi o SYBR Green (Applied Biosystems). A reação de PCR em tempo real (rt-PCR) foi realizada da seguinte maneira: $1,0 \mu \mathrm{l}$ de cDNA, $0,5 \mu$ l de oligonucleotídeo iniciador sense $(10 \mu \mathrm{M})$, $0,5 \mu \mathrm{l}$ de oligonucleotídeo iniciador anti-sense $(10 \mu \mathrm{M}), 7,5 \mu \mathrm{l}$ 
de Master Mix 2X (Applied Biosystems) e água suficiente para $15 \mu \mathrm{l}$ de reação. As amostras foram então incubadas a $95^{\circ} \mathrm{C}$ por $10 \mathrm{~min}$ e passaram por 40 ciclos de incubações a $95^{\circ} \mathrm{C}$ por 15 segundos, e a $56^{\circ} \mathrm{C}$ por 45 segundos. Os oligonucleotídeos utilizados (Sigma-Aldrich, USA) foram:

GAPDH

forward primer 5'-TGCACCACCAACTGCTTAGC-3';

reverse primer 5'-GCCCCACGGCCATCA-3');

BDNF

forward: 5'-ATGCTCAGCAGTCAAGTGCCTTTGG-3';

reverse:5'- GCCGAACCCTCATAGACATGTTTGC-3'),

NGF

forward: 5'-ACCCAAGCTCACCTCAGTGTCTGG-3';

reverse: 5'-CATTACGCTATGCACCTCAGAGTGG-3')

iNOS

forward primer: 5'- AAAGACCAGGCTGTCGTTGA-3'

reverse primer: 5'-ACGGGACCGGTATTCATTCT-3'

TNF-a

forward primer: 5'-AAATGGGCTCCCTCTATCAGTTC-3';

reverse primer: 5'-TCTGCTTGGTGGTTTGCTACGAC-3').

A quantificação de RNAm foi feita como um valor relativo a uma referência interna, o RNAm de GAPDH (gliceraldeído-3-fosfato desidrogenase), cuja expressão pode ser considerada inalterada nas condições experimentais aqui descritas.

Os valores de expressão do RNAm dos genes alvo e do GAPDH foram obtidos de um limiar arbitrário de fluorescência, analisado na fase exponencial da curva de 
amplificação, sendo o ciclo limiar (Ct) calculado. Foram calculados os Cts de cada amostra, em cada reação, para os quatro genes. Foi calculado o Ct médio de cada amostra, e o cálculo de expressão relativa foi feito através da subtração deste Ct médio do gene em estudo do Ct médio do gene GAPDH, obtendo-se o $\triangle \mathrm{Ct}$.

Como não é usual a utilização da expressão relativa de um determinado gene em valores de $\Delta \mathrm{Ct}$, em seguida foi realizada a normalização do $\Delta$ Ct de cada grupo em estudo com o $\Delta \mathrm{Ct}$ do grupo 1 (controle). Devido às suas características logarítmicas de amplificação, foi determinado então o parâmetro $2^{-\Delta \Delta C t}$ para análise de expressão relativa do RNAm dos genes em estudo, que foi representado em nosso experimento, como mudança relativa em relação a um grupo controle (Relative Fold Change).

Foram selecionadas 5 amostras de cada grupo para compor a média, a análise estatística e a construção dos gráficos se deu através do software GraPhapad Prism ${ }^{\circledR}$ 5.0, utilizou-se a ANOVA de uma via seguido do teste de Barlett e do teste de Newmann-Keuls para comparação entre os grupos. Os níveis de significância assumidos foram $\leq 0,05$.

\section{RESULTADOS e DISCUSSÃO}

Quanto a análise realizada pelo IFC, em relação ao grupo controle (sedentário), é possível constatar um discreto aumento nos valores do IFC do $7^{\circ}$ para $014^{\circ}$ dia, sem diferença, no entanto, do $14^{\circ}$ ao $21^{\circ}$ dia os valores 
aumentam drasticamente onde é possível constatar diferença comparado aos dias anteriores $(F(3,32)=10,02$; $p<0,001)$.

O grupo 2 mostra resultados em todos os períodos, a diferença se deu no $14^{\circ}$ dia contra o $1^{\circ}$ e $7^{\circ}$ dia e no $21^{\circ}$ dia também contra $01^{\circ}$ e $7^{\circ}$ dia não houve diferença entre o $14^{\circ}$ e $21^{\circ}$ dia $(F(3,32)=18,67 ; p<0,001)$.

O grupo 3 mostra um padrão semelhante ao grupo 2, a diferença se deu no $14^{\circ}$ dia contra o $1^{\circ}$ e $7^{\circ}$ dia, já no $21^{\circ}$ dia houve diferença contra todos os demais períodos, $1^{\circ}, 7^{\circ}$ e $21^{\circ}$ dias, $(F(3,32)=39,56 ; p<0,001)$.

No grupo 4 também se observa evolução nos valores de IFC, com diferença já no $7^{\circ}$ dia comparado ao $1^{\circ}$, o $14^{\circ}$ apresenta diferença também contra o $1^{\circ}$ dia enquanto o $21^{\circ}$ dia apresenta diferença contra todos os outros $(F(3,32)=20,16 ; p<0,001)$.

A Figura 1 mostra os gráficos referentes aos dados do IFC, com a evolução de cada grupo ao longo do processo de experimentação.

Como meio de treinamento físico o nado é eficaz pois tanto na fase aguda quanto na crônica foi capaz de acelerar o processo de regeneração, embora ainda não haja consenso sobre a melhor hora de se iniciar o exercício e o período adequado de treinamento ${ }^{18,23}$.

Considerando o contexto do exercício é possível especular que os estímulos táteis, térmicos e proprioceptivos da natação favoreçam o processo de regeneração através da ativação cruzada ${ }^{25}$ visto que, durante o processo exige-se a 
ativação muscular dos membros bilateralmente ${ }^{23}$. Na análise individual do desempenho dos animais por grupo foi possível notar que independentemente do grupo constatou-se que a recuperação funcional chega para todos por volta do $21^{\circ}$ dia após a, a exceção foi o grupo 2 que não mostrou diferença do $21^{\circ}$ para o $14^{\circ}$ dia após a lesão.

G1

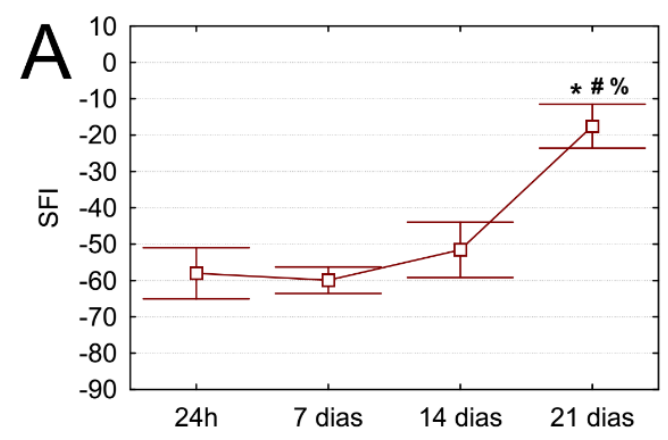

G3

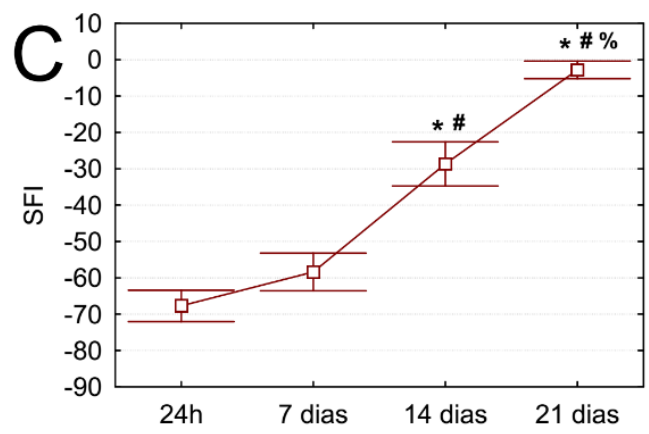

G2

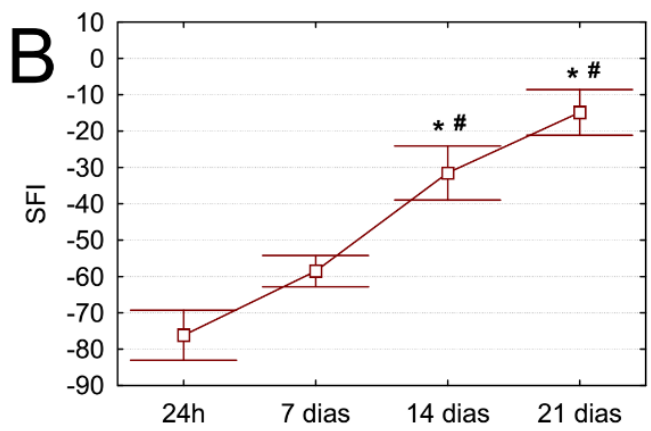

G4

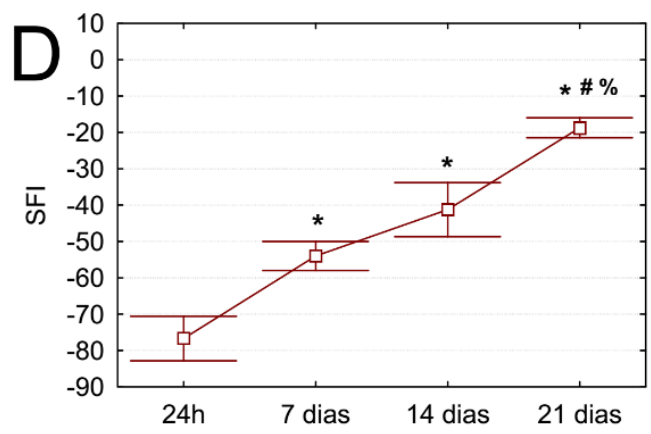

Figura 1. Valores do Índice Funcional do Ciático (SFI) ao longo de 21 dias de experimentação (A) grupo controle, (B) grupo 2, (C) grupo 3, (D) grupo 4. (*) Diferenças significantes em relação ao primeiro dia pós-axonotmese; (\#) Diferenças significantes em relação ao sétimo dia pós-axonotmese; (\%) Diferenças significantes em relação ao décimo quarto dia pós-axonotmese $(p<0,001)$.

Em relação aos grupos exercitados foi possível observar uma real diferença, sobretudo no $14^{\circ}$ dia após a lesão onde tais grupos mostraram diferença contra o primeiro dia após a lesão. Além disso os grupos 2 e 3 no $14^{\circ}$ dia apresentaram diferença contra o $7^{\circ}$ dia. Os dados apontam para uma 
melhora mais rápida dos grupos exercitados em relação ao controle, começando por volta do $14^{\circ}$ dia (exceção do grupo 4 que mostrou diferença do $7^{\circ}$ para $01^{\circ}$ dia após a lesão), já que, ao observar o gráfico do IFC do grupo controle não observa-se diferença entre os períodos $1^{\circ}, 7^{\circ}$ e $14^{\circ}$ dia após a lesão.

Quanto a comparação entre os grupos exercitados contra o controle, observa-se que a diferença ocorre no período de 14 dias após a lesão nervosa nos grupos 2 e 3 , e no período de 21 dias após a lesão no grupo 3. O grupo 4 não apresentou diferença do controle em nenhum dos períodos de registro do IFC.

Pesquisas anteriores de nosso laboratório, utilizando roda motorizada para promover o exercício em ratos durante os períodos de 7, 14 e 21 dias após axonotmese, geraram resultados de IFC divergentes dos nossos ${ }^{26}$. Neste experimento, a respeito da melhora funcional não foi observada diferença do grupo controle para os grupos exercitados, mostrando um padrão semelhante de evolução em todas as curvas do gráfico. Como visto, em nossos experimentos o G2 (exercitado diariamente) e o G3 (exercitado sete dias após a lesão) mostraram diferença do grupo controle (14 dias após a lesão G2 e G3 e 21 dias após a lesão G3). Entretanto, os autores sugerem uma aparente vantagem para os grupos exercitados contra o controle, fato este também observado neste nosso trabalho.

Independentemente do grupo estudado, com 21 dias pós lesão é possível constatar que já ocorre uma recuperação 
da função motora de forma homogênea, contudo, é de se esperar com 21 dias uma recuperação funcional de forma espontânea. Tal recuperação é constatada quando se observa que todos os grupos atingem valores de IFC próximos de zero. O período que compreende do $21^{\circ}$ ao $28^{\circ}$ dia é crucial para o pico de reinervação, o que dá base para a melhora funcional observada nos valores do IFC de nosso estudo27.

Nossos resultados estão de acordo com outro trabalho que utilizou o IFC para avaliar uma lesão nervosa tipo axonotmese, após submeterem ratos ao exercício diário através do nado, durante uma hora, na fase aguda (24 horas pós-lesão) e crônica (quatorze dias pós-lesão) ${ }^{23}$. Neste estudo o IFC foi mensurado nos dias 7,14,21 e 28 após a lesão. Os autores observaram que houve melhora na avaliação funcional dos animais que foram submetidos ao exercício, independentemente do início tanto na fase aguda quanto crônica. É importante destacar que o grupo que realizou atividade na fase aguda logo após a lesão apresentou vantagem contra os demais grupos, tal vantagem foi observada nos valores do IFC, ainda que não apresentassem valores significativos.

Um estudo que submeteu os animais também ao nado forçado, mostrou que o exercício não retardou e nem acelerou o processo de regeneração, e que no $21^{\circ}$ dia póslesão todos os grupos haviam chegado próximo ao parâmetro do normalidade ${ }^{28}$. Quando confrontados com os nossos dados, estes resultados mostram uma semelhança 
parcial, uma vez que, em nossos experimentos o G2 e G3 mostraram ser superiores aos demais grupos no período de 14 dias pós-lesão. Após 21 dias a recuperação funcional apresentou valores próximos do normal para todos os grupos não havendo diferença estatística. Podemos supor que as diferenças quando existentes entre os resultados de nosso estudo comparado com os demais, devem-se a inúmeras variáveis tais como tipo de exercício, intensidade e frequência com que foi empregado, já que, em nenhum dos trabalhos citados houve protocolo idêntico de treinamento.

É possível constatar no período de 24 horas após a lesão que não houve diferença entre os grupos, fato esperado devido a lesão ser feita de forma uniforme em todos os animais. No período de 7 dias após a lesão observa-se uma tendência positiva nos grupos exercitados (2, 3 e 4), porém não há diferença.

A Figura 2 apresenta a comparação dos valores de IFC entre os grupos em cada período de análise.

O gráfico referente ao período de 14 dias após a lesão mostra o grupo 2 e 3 com diferença em relação ao grupo controle, não há diferença entre eles, o grupo 4 mantém valores de IFC mais positivos em relação ao controle, porém sem diferença $(F(3,32)=10,09 ; p<0,01)$. No $21^{\circ}$ dia após a lesão é possível constatar diferença apenas no grupo 3 contra o controle $(F(3,32)=12,39 ; p<0,01)$.

Nossos resultados a respeito dos elementos quantificados através da técnica de RT-PCR, mostraram valores muito discrepantes entre os grupos (Figura 3). É 
sabido que fatores neurotróficos tais como o BDNF e o NGF são essenciais para o processo de regeneração nervosa após a lesão 28,29 .
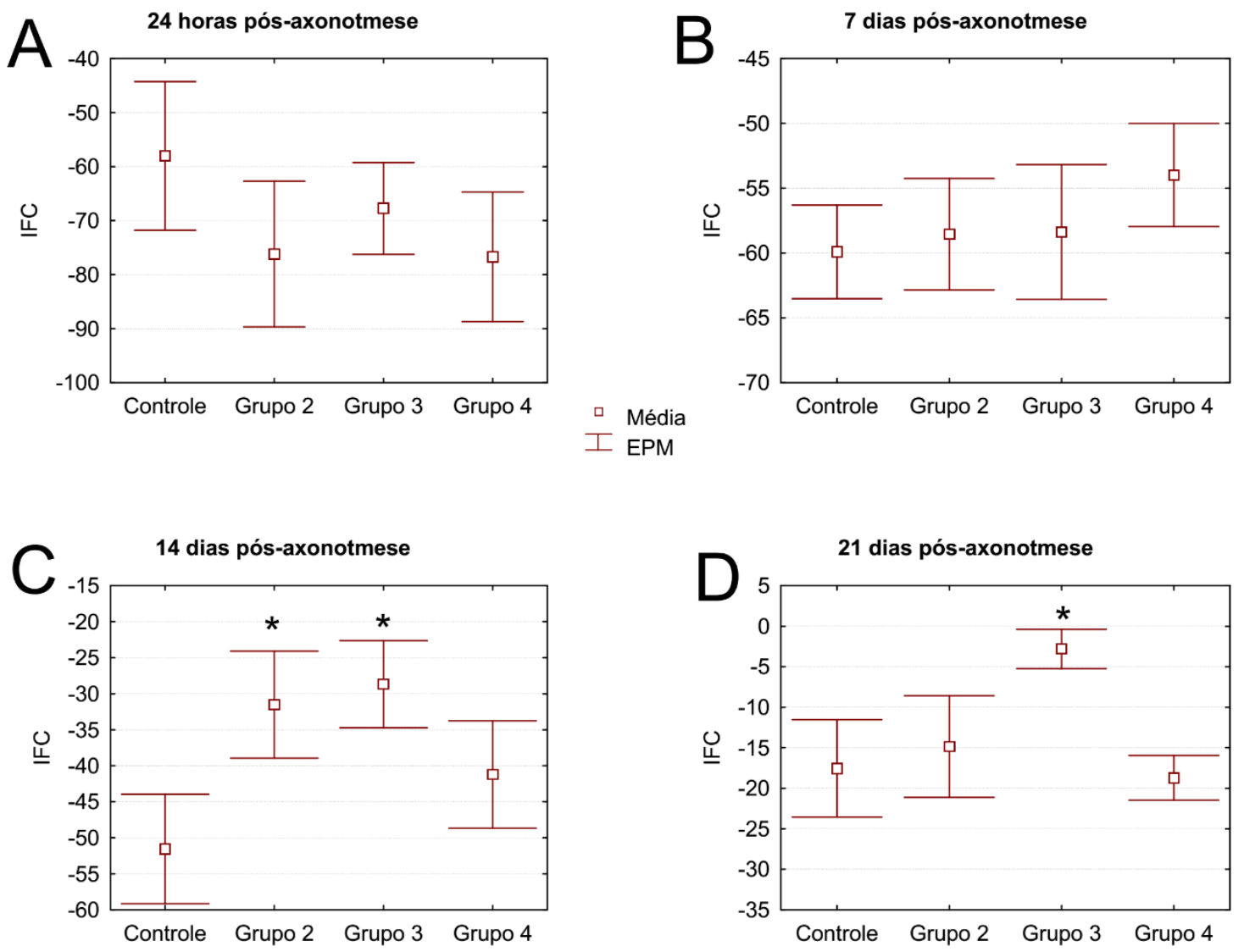

Figura 2. Comparação dos Valores do Índice Funcional do Ciático (IFC) entre grupos referentes aos períodos de (A) 24 horas pós-axonotmese, (B) 7 dias após axonotmese, $(C) 14$ dias pós-axonotmese e (D) 21 dias pós-axonotmese. $\left(^{*}\right)$ Diferenças significantes em relação ao grupo controle $(p<0,001)$.

Um estudo mensurou a expressão do RNAm tanto do BDNF quanto do NGF em nervos isquiáticos de ratos após lesão. Os autores mostram um aumento acentuado destes fatores de forma progressiva até o $21^{\circ}$ dia pós lesão, mesmo quando o animal não é submetido a nenhum tipo de atividade ${ }^{30}$. 

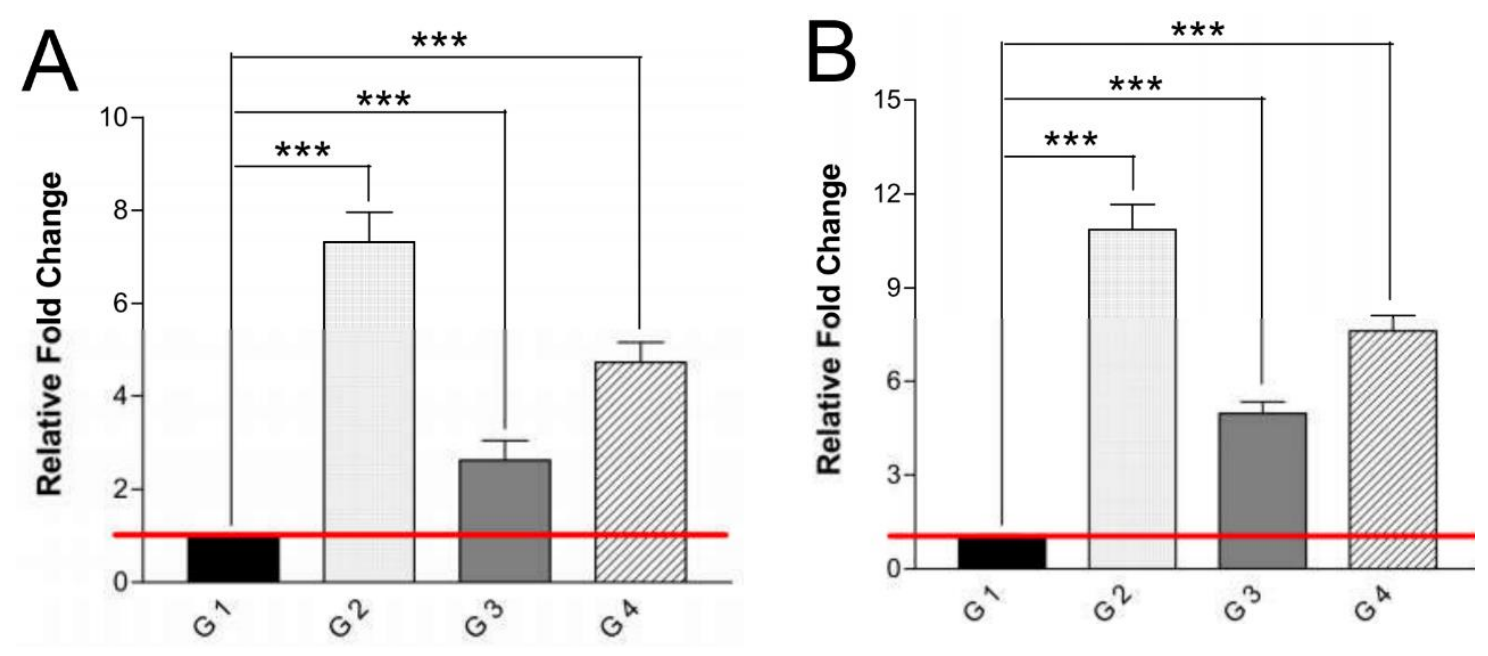

Figura 3. Quantificação da expressão gênica de (A) BDNF e (B) NGF 21 pósaxonotmese. $(* * *)$ mudanças relativas ao grupo controle (G1).

Houve um aumento na expressão de BDNF e NGF em ratos exercitados através da esteira, contra ratos não exercitados. Os autores também alertam para o fato de que exercícios muito extenuantes podem ter efeitos deletérios durante a reinervação, pela inibição na produção dos fatores neurotróficos, desta forma é aconselhável utilizar protocolos de exercícios mais brandos a fim de se conseguir efeitos positivos $^{31}$.

Diversas pesquisas mostram que ratos exercitados tem um aumento na expressão dos fatores neurotróficos BDNF e NT - 3, todos estes autores utilizaram a esteira como meio de promover o exercício físico 3,22,32.

Como o padrão de expressão do BDNF e NGF foi semelhante em cada grupo podemos discuti-los em conjunto.

Nossos resultados estão de acordo com os trabalhos citados anteriormente, para todos os grupos exercitados 
houve um aumento na expressão dos fatores neurotróficos mensurados. Este aumento foi visto de forma mais acentuada no G2 (exercitado diariamente), seguido do G4 que realizou exercício em dias alternados, já o G3 que realizou atividade tardia, apresentou menores níveis de expressão dentre os grupos exercitados. Parece-nos que a atividade realizada logo após a lesão influencia os níveis de expressão do BDNF e NGF, ao menos até o $21^{\circ}$ dia, já que, os grupos com maior expressão foram os que iniciaram 0 exercício vinte e quatro horas após a lesão (G2 e G4). Outro fator é a frequência com que o exercício é feito, visto que, dentre os grupos que realizaram a atividade vinte e quatro horas após a lesão, o G2 apresentou valores maiores que o G4.

Como mostrado nos resultados do IFC, no registro referente ao $21^{\circ}$ dia após a lesão, todos os grupos apresentaram parâmetros funcionais levemente superiores ao controle. Pode-se então fazer uma correlação positiva dos dados funcionais e biomoleculares uma vez que todos os grupos exercitados tiveram valores superiores de expressão do BDNF e NGF. O exercício foi capaz de aumentar a expressão de BDNF e NGF, mesmo no G4 que não teve uma recuperação funcional diferente do grupo controle.

Além dos fatores neurotróficos optamos por quantificar também a enzima iNOS e a citocina TNF-a (Figura 4), ambas com função pró-inflamatória?. 

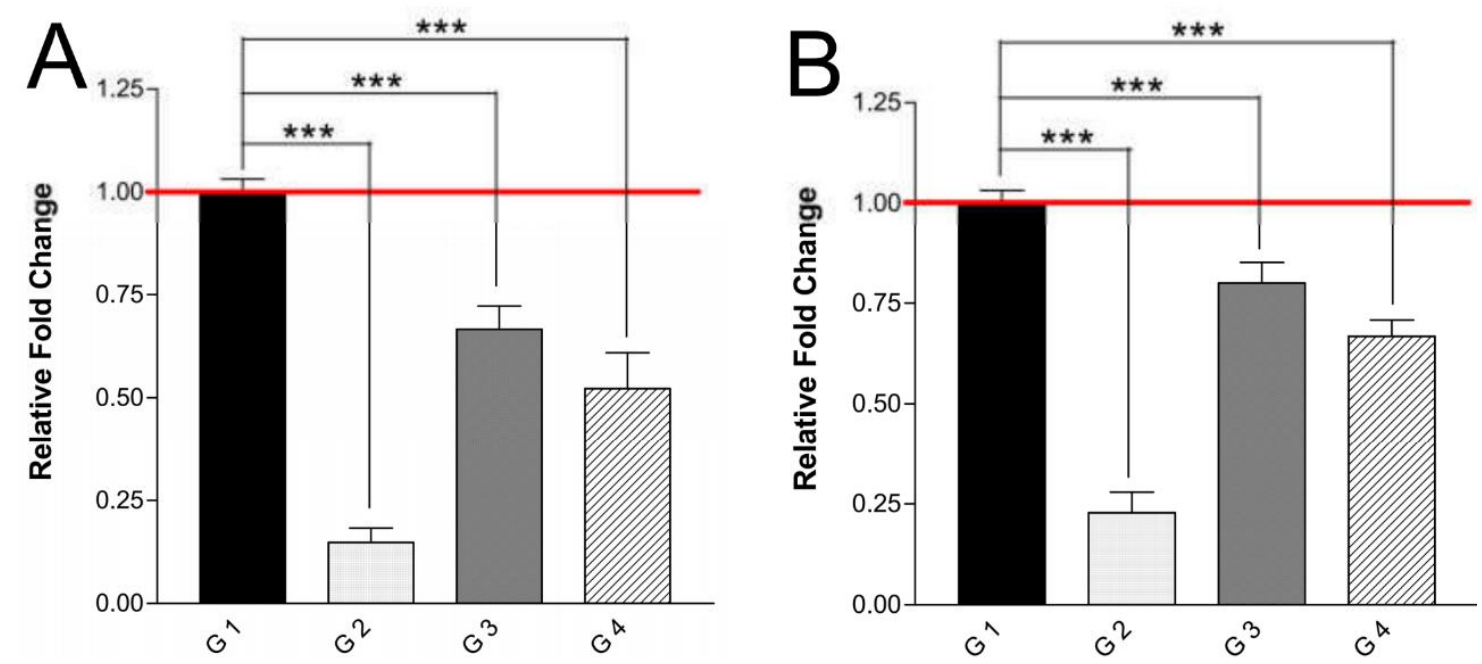

Figura 4. Quantificação da expressão gênica de (A) iNOS e (B) TNF-a 21 pósaxonotmese. $(* * *)$ mudanças relativas ao grupo controle $(\mathrm{G} 1)$.

Como visto em nossos resultados, o grupo controle mostrou uma expressão do RNAm referente a iNOS extremamente alta quando comparado aos grupos exercitados. Nossos resultados são semelhantes a outros que quantificaram a iNOS em ratos após a lesão e mostraram índices altíssimos de expressão decaindo ao longo do tempo, concluindo que esta expressão em excesso não favorece 0 processo de regeneração nervosa, e que o papel da iNOS na regeneração ainda precisa ser totalmente elucidado ${ }^{11}$.

Os demais grupos exercitados, quando comparados ao grupo controle mostraram uma expressão do RNAm referente a iNOS bem menores, sobretudo o G2, seguido do G4 e G3.

Nossos resultados a respeito do TNF-a, também se assemelham ao padrão encontrado com a iNOS, ou seja, baixos nos grupos exercitados começando pelo G2, seguido do G4 e G3, e altos no grupo controle. Esses dados se assemelham a de outro estudo ${ }^{33}$ que ao analisar o nervo 
isquiático em diferentes grupos de animais, encontraram níveis de TNF-a diminuídos nos grupos que praticaram algum tipo de exercício, comparados com o controle não exercitado. Outras citocinas pró inflamatórias tais como a interleucina 1 beta $(I L-1 \beta)$ e a interleucina 6 (IL-6) também foram mensuradas e mostraram redução em grupos exercitados ${ }^{33}$.

Analisando os elementos quantificados nos três grupos exercitados pode-se constatar uma correlação destes quatro elementos em cada grupo, ou seja, o G2 foi o que apresentou maiores níveis de expressão de BDNF e NGF, em consequência foi também o que apresentou menores níveis de iNOS e TNF-a. O G3 apresentou menores níveis de BDNF e NGF e maiores níveis de iNOS TNF-a. Já o G4 apresentou valores intermédios entre o os grupos 2 e 3, sendo estes superiores ao G3 e inferiores ao G2 para o BDNF e NGF. Como também, valores inferiores ao G3 e superiores ao G2 para a iNOS e TNF-a.

Além disso, o padrão de expressão do BDNF e NGF difere quando se compara estes fatores no mesmo grupo, isto é, o BDNF nos grupos 2, 3 e 4 apresentou expressão menor quando comparado ao NGF nos mesmos grupos. Acreditamos que esta diferença se dá pelo tipo desigual de expressão uma vez que o BDNF tem aumento de sua expressão chegando ao pico no sétimo e/ou décimo quarto dia após a lesão. Já o NGF apresenta um formato de expressão bifásico, atingindo um pico de expressão muito alto por volta da segunda semana pós-lesão e mantendo este 
pico por um longo tempo à medida que o BDNF tende a diminuir ${ }^{34,35}$.

\section{CONCLUSÃO}

Diante do exposto, nossos dados apontam para um efeito benéfico do exercício no processo de regeneração nervosa periférica. Não podemos afirmar categoricamente que houve um aumento na velocidade de regeneração nervosa nos grupos que realizaram exercício, mas é evidente a ligeira melhora funcional mostrada por estes grupos bem como o aumento na expressão de fatores neurotróficos BDNF e NGF e a diminuição do processo inflamatório demonstrada pela redução na expressão da citocina TNF-a e da enzima iNOS.

\section{REFERÊNCIAS}

1.Toth C. Peripheral nerve injuries atributable to sport and recreation. Phys Med Rehabil 2009;20:77-100.

http://dx.doi.org/10.1016/j.pmr.2008.10.012

2. Noble J, Munro CA, Prasad VS, Midha R. Analysis of upper and lower extremity peripheral nerve injuries in a population of patients with multiple injuries. J Trauma 1998;1:116-22.

https://doi.org/10.1097/00005373-199807000-00025

3.Sarzenski TM. Efeitos do treinamento físico sobre a regeneração do nervo isquiático no diabetes experimental (Tese). Porto Alegre: Instituto de ciências básicas e da Saúde, Universidade Federal do Rio Grande do Sul, 2010, 167p. http://hdl.handle.net/10183/60998

4.Gordon $\mathrm{T}$. The role of neurotrophic factors in nerve regeneration. Neurosurg Focus 2009;3:1-10.

https://doi.org/10.3171/foc.2009.26.2.e3

5.Sobral LL, Oliveira LS, Takeda SYM, Somazz MC, Montebello MIL, Teodori RM. Immediate versus later exercises for rat sciatic nerve regeneration after axonotmesis: histomorphometric and functional analyses. Brazilian J Phys Ther 2008;12:311-6.

https://doi.org/10.1590/S1413-35552008000400010

6. Rotshenker S. Wallerian degeneration: the innate-immune response to traumatic nerve injury. J Neuroinflamm 2011;8:1-15.

https://doi.org/10.1186/1742-2094-8-109 
7.Ydens E, Cauwels BA, Goethals S, Peeraer L, Lornet G, AlmeidaSouza $L$, et al. Acute injury in the peripheral nervous system triggers an alternative macrophage response. J Neuroinflamm 2012;9:176-81. https://doi.org/10.1186/1742-2094-9-176

8.Shamash F, Seichert F, Rotshenker S. The cytokine network of wallerian degeneration: tumor necrosis factor-alpha, interleukin-1 alpha, and interleukin-1 beta. J Neurosci 2002;22:2052-60. https://doi.org/10.1523/jneurosci.22-08-03052.2002

9. Conti G, Rostami A, Scarpini E, Baron P, Galimberti D, Bresolin N, et al. Inducible nitric oxide synthase (iNOS) in immune-mediated demyelination and Wallerian degeneration of the rat peripheral nervous system. Exper Neurol 2004;187:350-8.

https://doi.org/10.1016/j.expneurol.2004.01.026

10.Emirandetti GFS, Zanon RG, Oliveira ALR. Spinal motoneuron synapctic plasticity after axotomy in the absence of inducible nitric oxide synthase. J Neuroinflamm 2010;7:1-16.

https://doi.org/10.1186/1742-2094-7-31

11. Lin $\mathrm{H}$, Hou $\mathrm{C}$, Chen D. Altered expression of inducib le nitric oxide synthase after sciatic nerve injury in rat. Cell Biochem Biophys 2011;61:261-5. https://doi.org/10.1007/s12013-011-9192-6

12. Hall S. The response to injury in the peripheral nervous system. J Bone Joint Surg Am 2005;87:1309-19. https://doi.org/10.1302/0301$620 x .87 \mathrm{~b} 10.16700$

13. Wihelm JC, Xu M, Cucoranu D, Chmielewski S, Homes T, Lau KS, et al. Cooperative roles of BDNF expression in neurons and schwann cells are modulated by exercise to facilitate nerve regeneration. J Neurosci 2012;32:2002-9. https://doi.org/10.1523/JNEUROSCI.1411-11.2012 14.Sebben DA, Cocolichio F, Schimitt AP, Curra MD, Viegas P, Tres GL, et al. Effect of neurotrophic factors on peripheral nerve repair. Sci Med 2011;21:81-9.

https://www.researchgate.net/publication/277212967 Effect of neur otrophic factors on peripheral nerve repair Abstract in English

15.Aron L, Klein R. Repairing the parkinsonian brain with neurotrophic factors. Cell Press Trends Neurosci 2011;34:88-100. https://doi.org/10.1016/j.tins.2010.11.001

16. Madduri S, Gander B. Schwann cell delivery of neurotrophic factors for peripheral nerve regeneration. J Periph Nervous Sys 2010;15:93103. https://doi.org/10.1111/j.1529-8027.2010.00257.x

17.Ilha J, Araujo RT, Malysz T, Hermel EES, Rigon P, Xavier LL, et al. Endurance and Resistance Exercise Training Programs Elicit Specific Effects on Sciatic Nerve Regeneration After Experimental Traumatic Lesion in Rats. Neurorehab Neural Repair 2008;22:355-66. https://doi.org/10.1177/1545968307313502

18.Udina E, Puigdemasa A, Navarro X. Passive and active exercise improve regeneration and muscle reinnervation after peripheral nerve injury in the rat. Muscle Nerve 2011;43:500-9. https://doi.org/10.1002/mus.21912 
19.Gutmann E, Jakoubek B. Effect of increased motor activity on regeneration of the peripheral nerve in young rats. Physiol Bohemoslovenica 1963;12:463-8.

20.Tam SL, Archibald V, Jassar B, Tyreman N, Gordon T. Increased neuromuscular activity reduces sprouting in partially denervated muscles. J Neurosci 2001;15:654-67.

https://doi.org/10.1523/JNEUROSCI.21-02-00654.2001

21.Soucy M, Sebum K, Gardiner P. Is increased voluntary motor activity beneficial or detrimental during the period of motor nerve regeneration/reinnervation. Can J Appl Physiol 1996;21:218-24. https://doi.org/10.1139/h96-018

22.Molteni R, Zheng JQ, Ying Z, Gomez-Pinilla F, Twiss JL. Voluntary exercise increases axonal regeneration from sensory neurons. Proc Natl Acad Sci 2004;101:8473-8.

https://doi.org/10.1073/pnas.0401443101

23.Teodori RM, Betini J, Oliveira LS, Sobral LL, Takeda SYM, Montebelo MIL. Swimming exercise in the acute or late phase after sciatic nerve crush accelerates nerve regeneration. Neural Plas 2011;1:1-8. https://doi.org/10.1155/2011/783901

24.Bain JR, Mackinnon SE, Hunter DA. Functional evaluation of complete sciatic, peroneal, and posterior tibial nerve lesions in the rat. Plas Reconstruc Surg 1989;1:129-36.

https://doi.org/10.1097/00006534-198901000-00024

25.Munn J, Herbert RD, Hancock MJ, Gandevia SC. Resistance training for strength: effect of numver of sets and contraction speed. Med Sci Sports Exerc 2005; 9:1622-6.

https://doi.org/10.1249/01.mss.0000177583.41245.f8

26.Possamai F, Pacheco DR, Santos TS, André ES. Repercussões morfológicas e funcionais do exercício sobre a regeneração nervosa periférica. Fisioter Mov 2012;25:617-27.

http://dx.doi.org/10.1590/S0103-51502012000300017

27.Gorio A, Carmignoto G, Finesso M, Polato P, Nunzi GM. Muscle reinnervation II. Sprouting synapse formation and repression. Neurosci 1983;3:403-16. https://doi.org/10.1016/0306-4522(83)90188-4

28.Araújo RT. Efeitos do treinamento físico na água aquecida sobre a recuperação funcional e a regeneração nervosa periférica após lesão do nervo isquiático em ratos machos adultos. (Dissertação). Porto Alegre: Universidade federal do Rio Grande do Sul, 2008, 76p.

29. Campbell WW. Evaluation and management of peripheral nerve injury. Clin Neurophysiol 2008;199:1951-65.

https://doi.org/10.1016/j.clinph.2008.03.018

30. Meyer M, Matsuoka I, Wetmore C, Olson L, Thoenen H. Enhanced synthesis of brain derived neurotrophic factor in the lesioned peripheral nerve: Different mechanisms are responsible for the regulation of BDNF and NGF mRNA. J Cell Biol 1992;1:45-54.

https://doi.org/10.1083/jcb.119.1.45

31.Cobianchi S, Diaz LC, Jaramillo J, Navarro X. Differential effects of activity dependent treatments on axonal regeneration and neuropathic 
pain after peripheral nerve injury. Exp Neurol 2013;240:157-67. https://doi.org/10.1016/j.expneurol.2012.11.023

32.Gómez-Pinilla F, Ying Z, Roy RR, Molteni R, Edgerton VR. Voluntary exercise induces a BDNF-mediated mechanism that promotes neuroplasticity. J Neurophysiol 2002;88:2187-95. https://doi.org/10.1152/jn.00152.2002

33.Bobinski F, Martins DF, Bratti T, Mazzardo-Martins L, WinkelmannDuarte EC, Guglielmo LGA, et al. Neuroprotective and neuroregenerative effects of lowintensity aerobic exercise on sciatic nerve crush injury in mice. Neurosci 2011;194:337-48. https://doi.org/10.1016/j. neuroscience.2011.07.075

34.Funakoshi $H$, Frisén J, Barbany G, Timmusk $T$, Zachrisson $O$, Verge VMK, et al. Differential expression of mRNAs for neurotrophins and their receptors after axotomy of the sciatic nerve. J Cell Biol 1993;2:455-65. https://doi.org/10.1083/jcb.123.2.455

35. Heumann R, Korching S, Bandtlow C, Thoenen $\mathrm{H}$. Changes of nerve growth factor synthesis in nonneural cells in response to sciatic nerve transection. J Cell Biol 1987;2:1623-31.

https://doi.org/10.1083/jcb.104.6.1623 